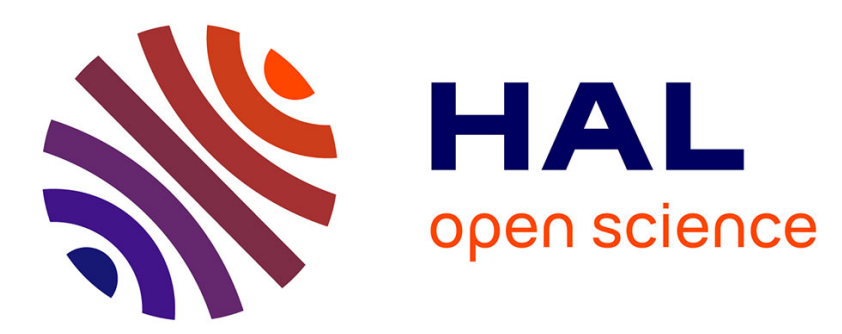

\title{
An Experimental Investigation of Condition Monitoring for Notched Rotors Through Transient Signals and Wavelet Transform
}

Jean-Jacques Sinou

\section{- To cite this version:}

Jean-Jacques Sinou. An Experimental Investigation of Condition Monitoring for Notched Rotors Through Transient Signals and Wavelet Transform. Experimental Mechanics, 2009, 49, pp.683-695. 10.1007/s11340-008-9193-6 . hal-00411735

\section{HAL Id: hal-00411735 \\ https://hal.science/hal-00411735}

Submitted on 26 Sep 2012

HAL is a multi-disciplinary open access archive for the deposit and dissemination of scientific research documents, whether they are published or not. The documents may come from teaching and research institutions in France or abroad, or from public or private research centers.
L'archive ouverte pluridisciplinaire HAL, est destinée au dépôt et à la diffusion de documents scientifiques de niveau recherche, publiés ou non, émanant des établissements d'enseignement et de recherche français ou étrangers, des laboratoires publics ou privés. 


\title{
An experimental investigation of condition monitoring for notched rotors through transient signals and wavelet transform
}

\author{
J-J. Sinou \\ Laboratoire de Tribologie et Dynamique des Systmes UMR-CNRS 5513 \\ Ecole Centrale de Lyon, 36 avenue Guy de Collongue, 69134 Ecully Cedex, France. \\ jean-jacques.sinou@ec-lyon.fr
}

\begin{abstract}
Experimental studies considering the dynamic transient signals of a notched rotor (i.e. a rotor with a transverse open crack) are investigated in order to examine the possibility of detecting the presence of open cracks in rotating machinery for low or high rotor accelerations.

Firstly, the orbital patterns, spectrum cascade plots of the Power Spectral Density, evolutions of the $2 \times$ amplitudes of rotor with and without an open transverse crack are compared and discussed in the case of low accelerations of the rotor system.

Secondly, the non-stationary vibration signals of the rotor with an open transverse crack at high accelerations are investigated. The timefrequency features and a tool based on the continuous wavelet transform (CWT) to detect open cracks in a rotor system are discussed.

It is demonstrated that both the continuous wavelet transform (CWT) and changes on the $2 \times$ harmonic components are robust indicators for crack detection.
\end{abstract}

\section{Introduction}

Structural damage detection and condition monitoring have been receiving increased attention in recent years due to their practical importance in many industrial applications. Extensive reviews have been compiled by Wauer [1] and Dimarogonas [2].

Generally, two types of approaches are suggested by different researchers. One monitoring changes in the resonant frequencies and in the mode shapes and other based on the change in non-linear dynamic responses during rotation of the notched shaft.

The first approach is an off-line process for rotating machinery. The modal tests and detection based on changes in modal parameters have to be carried out during static condition of rotor. Reviews of research works dealing with the problem of crack detection based on changes in modal parameters can be found in [3-6]. However, several researchers [7,8] have demonstrated that changes in modal properties are not always reliable and this type of damage identification technique can become very difficult.

The second approach focuses on the non-linear dynamic vibration of rotor during its rotation. Many 
researchers [9-14] indicated that the diagnosis of crack presence can be done by considering the appearances or/and changes in the steady-state vibration amplitudes of $1 \times, 2 \times$ and $3 \times$ harmonic components of steady-state response of the rotor system. They also proposed to exploit orbital patterns of the notched rotor at one-half of the first critical speed $[15,16]$. On the other hand, Bachschmid et al. $[17,18]$ proposed a model-based diagnostic approach with a least-squares identification for the detection of cracks in rotors. Darpe [19] proposed to use coupling of bending and longitudinal vibrations with periodic axial excitation to detect the crack presence. Han [20] illustrated that directional frequency response functions (d-FRFs) is a robust tool for investigating the presence or the propagation of the crack.

Then, non destructive detection of cracks in rotors based on transient non-linear signals have been developed [21-23]. For example, Sekhar [24] investigated the effects of different factors such as crack depth, unbalance eccentricity and acceleration influencing transient vibrations and concluded that the measurement of transient response when the rotor is passing through the critical speed or one-half of the critical speed can be used for the non destructive detection of cracks in rotors. Finally, some researchers [25-27] proposed to introduce time-scale signal processing tools based on wavelet transform due to the limitation of the conventional Fourier analysis that is suitable for steady state vibration signals, but provides a poor representation of signals well localized in time. This method for non-stationary signal analysis has been recently used for various fault diagnosis and damage localization [28-30]. However, few experimental researches could be found on the detection of cracks in rotating machinery with wavelet techniques.

So, the objectives of this work is to present an experimental study on the dynamic response of a rotor with a transverse open crack for low and high rotor's accelerations and to show the ability and feasibility of the application of Continuous Wavelet Transform (CWT) in the diagnostic of cracks in the rotating machinery using the non-stationary vibrations signals during machine run-up.

In this study, the type of crack that has been chosen is a transverse open crack: the crack that always remains open is perpendicular to the shaft axis. As explained by Sabnavis et al. [31], most experimental studies are focused on open cracks (called notches or gaping cracks) due to the fact that this crack type are easy to mimic in a laboratory environment.

Firstly, the conventional fast Fourier transform (FFT)-based spectral analysis method is used to analyze steady-state vibration signals of the rotor with and without crack. Secondly, the non-stationary transient signal of rotor with high accelerations is analyzed by using the continuous wavelet transform. The effectiveness of wavelet transforms for crack detection and monitoring in rotors will be illustrated for various experimental tests.

\section{Experimental Setup}

The test equipment used for the experiment include a test rig, motor speed control, eddy current displacement/proximity probes, and data acquisition interface unit that is controlled by the I-DEAS Software. The test rig as Figure 1 illustrates consists of an elastic shaft and a rigid disk. The rotor's shaft is simply supported at both ends (designed by Support 1 and Support 2 in Figure 1). The length of the shaft is $480 \mathrm{~mm}$ and its diameter is $10 \mathrm{~mm}$. The disc is mounted at the position $260 \mathrm{~mm}$ from the left end of the rotor. The diameter and thickness of the disc-rotor are $75 \mathrm{~mm}$ and $35 \mathrm{~mm}$, respectively. The rotor system is driven by an electric motor incorporated with a shaft through a flexible coupling. The first critical speed of the crack-free rotor is $1980 \mathrm{rpm}$. The rotor's crack is made at the position $240 \mathrm{~mm}$ by cutting a piece with width $0.2 \mathrm{~mm}$ and a non-dimensional depth of $\mu=1$ (corresponding to the loss of half the shafts area). It must be noted that the cut that has been made with a jeweler's saw introduces an open crack in the rotor. Indeed the lateral deflections being small, the slit may not completely close and would 


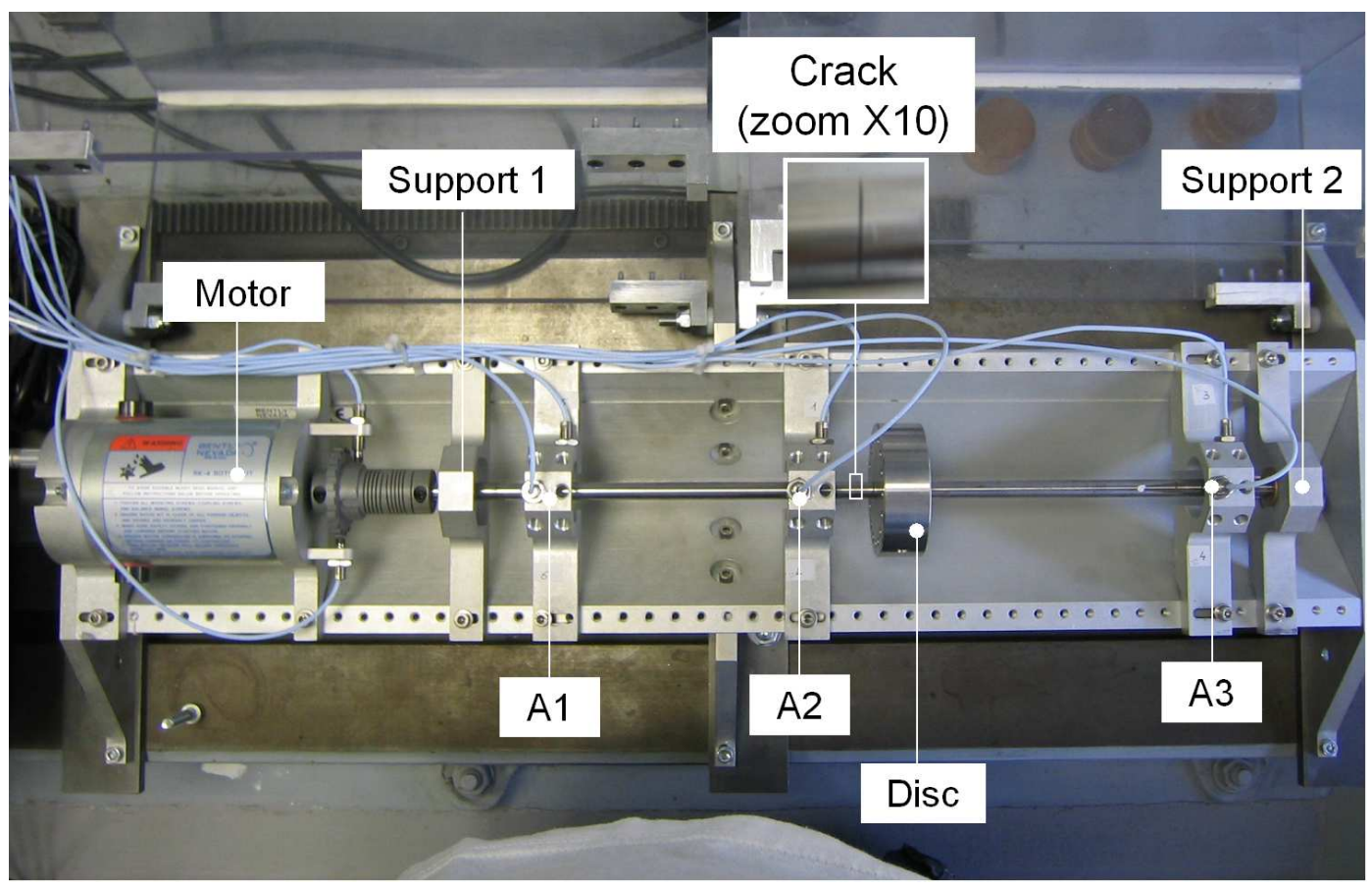

Figure 1: Test rig of the rotating machinery

not eventually breathe. So the rotor under study may be considered as a notched rotor (i.e. a rotor with an open transverse crack).

The vibration measurements are conducted by using six proximity probes that are mounted in both the horizontal and vertical directions, as indicated on Figure 1. They consist of two orthogonal sensors for each plane and are placed at $70 \mathrm{~mm}$ (plane A1), 210mm (plane A2) and 440mm (plane A3) from the left end of the shaft. Planes A1 and A3 are situated near the left and right supports respectively, and the plane A2 is near the crack's position.

The probes are connected to the National Instruments PCI-4472 channel dynamic signal acquisition devices, which is in turn connected to the PC. The data acquisition interface unit operation is controlled by the I-DEAS Software to collect and store vibration data. Then the data are transferred from I-DEAS Software to Matlab in order to be processed.

\section{Results and discussions}

\subsection{Steady-state dynamic responses in time domain}

\subsubsection{Orbital patterns and $2 \times$ amplitudes at low acceleration}

First of all, the dynamic responses of the healthy and notched shafts is analyzed for low acceleration of rotor $\left(20 \mathrm{rpm} . \mathrm{s}^{-1}\right)$. Figure 2 shows the vertical and horizontal vibrations of the rotor without and with open crack passing through its first critical speed in time domain.

An increase in amplitudes of vibration is observed with the notched rotor compared to the healthy ro- 
tor in both the vertical and horizontal amplitudes when the rotor is passing through its first critical speed (for $t=100 \mathrm{~s}$ ). Moreover, there is large increase of vibrations near the rotational speeds at one-half of the first critical speed (for $t=50 \mathrm{~s}$ ).

Evolutions of the orbital patterns of the healthy and notched rotors when the rotor is passing through one half of the first critical speed are shown in Figures 3 and 4. For the reader comprehension, the rotating speed is increasing from Figures 3(a) to 3(h) (from 4(a) to (h) respectively). It can be clearly observed that the presence of a transverse open crack induces a loop containing an important loop inside. When the rotating speed of the notched rotor reaches through half of the first critical speed, a rotation of the inside loop indicating a significant change in the phase and amplitude of the $2 \times$ vibration appears. For the healthy rotor, the orbit firstly changes from double loops to an outside loop (like a "eight"') and then a small inside loop is observed. This non-linear vibrations of the healthy rotor and the small contribution of super-harmonic components can be attributed to the bow-related side load on the shaft, the rotor anisotropy and the unbalance. Comparing the orbital patterns of the healthy and notched rotors ( 3 and 4), it can be concluded that the size of the inside loop and the orbital movements of the rotor through the passage of one-half of the first critical speed can be used as the signature of the presence of a open transverse crack in rotating machinery.

To identify the presence of sub critical response peaks of the dynamic responses of the healthy and notched shafts, spectrum cascade plots of the Power Spectral Density (PSD) which describes how the power of time series is distributed with frequency, are calculated (as previously explained the signal is assumed to be stationary for small intervals of time in this first section of the study). Figures 5-6(d) and 56(b) illustrate the power spectral density when the rotor is passing through the first critical speed $(\mathrm{t}=100 \mathrm{~s})$ and one-half of the first critical speed $(t=50 s)$. It is clearly observed that the $2 \times$ super-harmonic frequency component is more prominent than the rotational frequency near the rotational speeds at the $\frac{1}{2}$ of the first critical speed for the rotor without and with crack. However, the maximum value of power spectral density is obtained for the notched rotor. So an increase of the power spectral density at one-half of the critical speed can be used as an indicator of the presence of a transverse open crack in rotors. Then, for the both cases, only the $1 \times$ revolution vibration amplitude is present when the rotor is passing through its critical speed. Finally, before the $\frac{1}{2}$ of the critical speed (for $t=40 \mathrm{~s}$ ) and between $\frac{1}{2}$ and 1 of the critical speed (for $t=80 \mathrm{~s}$ ), the motions of the notched rotor are complicated due to existence of the $1 \times$ and $2 \times$ frequencies of the rotational speed in the vibration signals (see Figures $6(a)$ and (c)), whereas the motions of the crack-free rotor are principally described by the $1 \times$ revolution vibration amplitudes (see Figures 5-6(a) and (c)).

To clarify the contributions of the $n \times$ super-harmonic frequency components in run-up stages, the normalized conventional power spectral density cascade plots are drawn in Figures 7 for the rotor without and with an open crack. It is noted that the characteristic sub-critical response peaks and an average value of power spectral density can be estimated at various regular intervals of times due to the low acceleration of the rotor during the transient analysis (i.e. for each interval, the transient vibrations are assumed to be stationary). The normalized spectral density are defined by

$$
P S D_{\text {normalized }}=\frac{\log (P S D)-\log \left(P S D_{\min }\right)}{\log \left(P S D_{\max }\right)-\log \left(P S D_{\min }\right)}
$$

where $P S D_{\min }$ and $P S D_{\max }$ define the minimum and maximum values of the power spectral density on the speed range. The power spectral density is normalized in order to be able to compare the contributions and evolutions of the $n \times$ super-harmonic frequency components for the rotor with and without crack. The values of the normalized power spectral density varies from zero to unity. The physical values have 

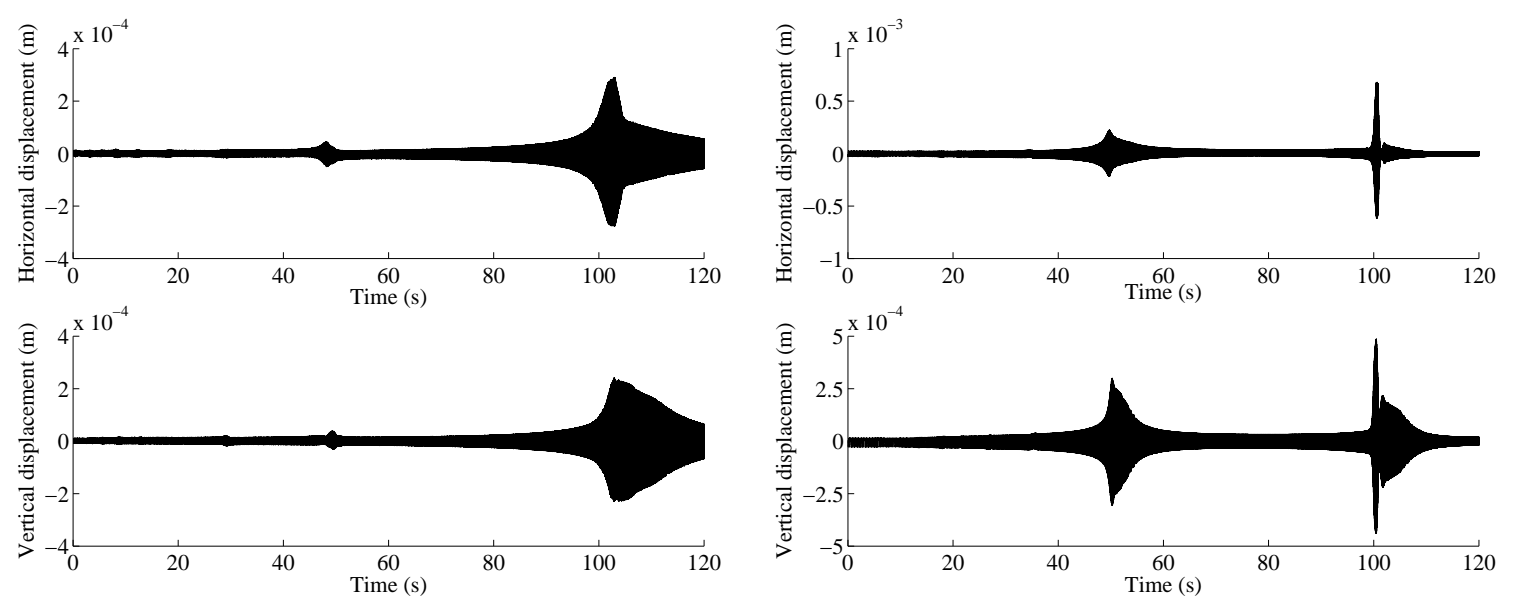

(a) Healthy rotor

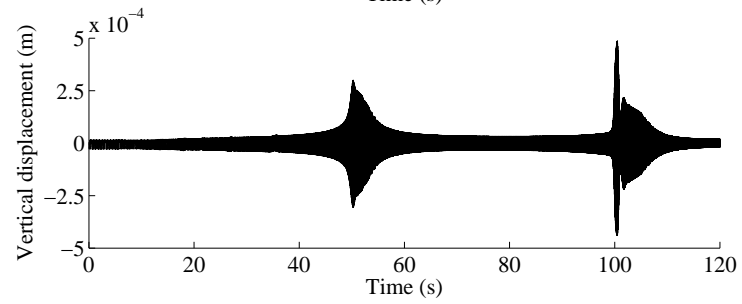

(b) notched rotor (case 4)

Figure 2: Dynamic responses of the rotor without and with an open crack passing through its first critical speed in time domain (plane A2)

been given in the previous power spectral density plots (see Figures 5 and 6).

As indicated in Figures 7, the contribution of $2 \times$ harmonic amplitudes for the notched rotor is more significant and greater than that of the healthy rotor when the rotor reaches one-half and one-third of the first critical speed for both the vertical and horizontal directions. Moreover, it can be observed that the $3 \times$ harmonic components are present in the horizontal direction when the rotor is passing through nearly the first critical speed. However, the differences of the $3 \times$ amplitudes for the healthy and notched rotors are not significant enough in order to be used as a diagnostic tool.

In conclusion, these experimental results reflect the fact that the contributions of the $2 \times$ amplitudes and the orbital patterns at one-half of the first critical speeds could be key indicators for the detection of transverse open cracks in a rotating shaft.

\subsection{Amplitudes for low and high accelerations of the rotor}

If the rotor's acceleration is very high, the vibration responses are typically transient along with frequency and amplitude modulation because of high acceleration of the rotor system, as illustrated in Figures 8 . In this case, the conventional Fourier analysis can provide a poor representation of signals well localized in time. So, the evolutions of the orbit patterns or the conventional spectrum cascade plots can not be used for analyzing vibration characteristics and for detecting the presence of a transverse crack in rotor clearly.

However, the maximum amplitudes for one-half of the first critical speed and the critical speed can be investigated for various accelerations of the rotating machinery. The results are presented in Figures 9. The various accelerations are given in Table 1 for each case. First of all, it clearly appears that increasing the rotor's acceleration decreases the amplitudes at the first critical speed both in the vertical and horizontal amplitudes (see Figure 9(a)).

Then, it is observed that the maximum horizontal and vertical amplitudes at one-half the first critical speed are not greatly affected by the rotor's acceleration (see Figure 9(b)). This reflects the fact that the $2 \times$ super-harmonic frequency components for the notched rotor are predominant not only at one-half of 


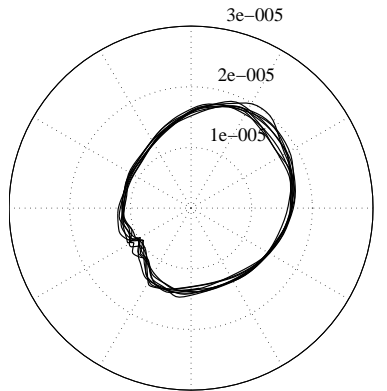

(a)

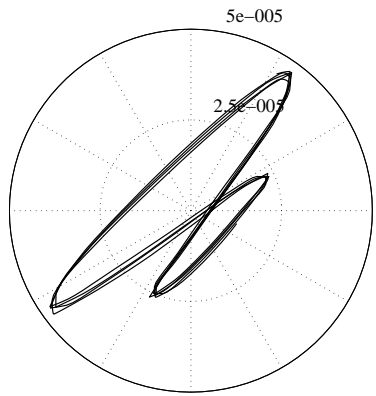

(e)

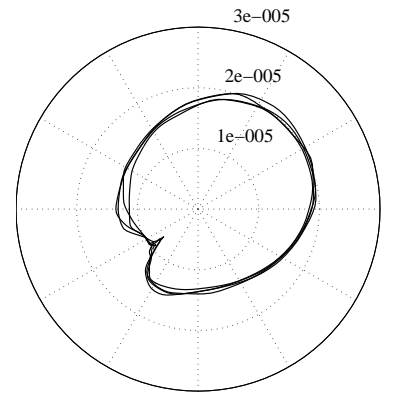

(b)

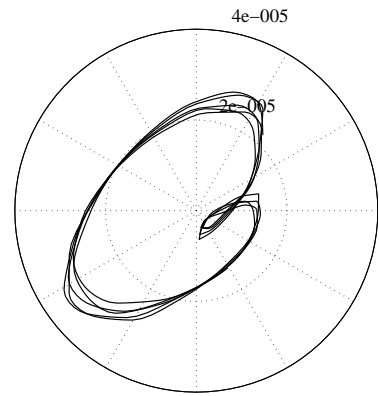

(f)

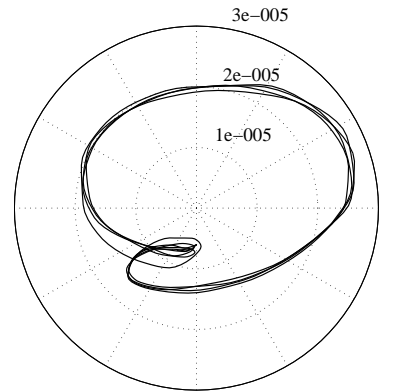

(c)

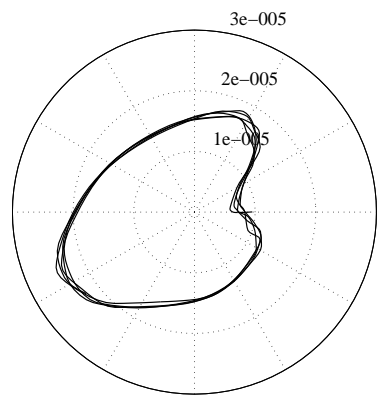

(g)

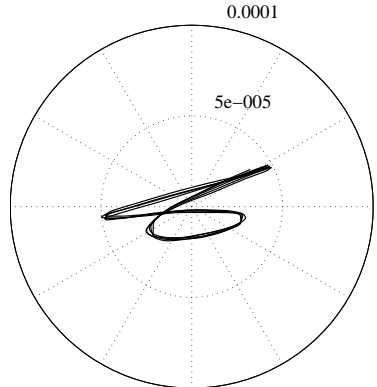

(d)

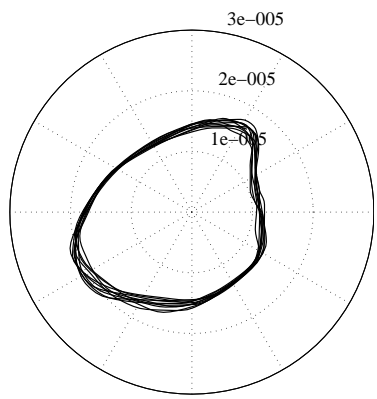

(h)

Figure 3: Evolutions of the orbital patterns at one-half of the first critical speed (from (a) to (h)) for the healthy rotor at plane A2

the first critical speed but also in its vicinity (as previously seen in Figures 5 and 7(c) and (d)).

Finally, Figures 10 show the evolutions of the maximum amplitudes versus unbalance : it clearly appears that the maximum amplitudes at the first critical speed corresponds mainly to the unbalance effect whereas the maximum amplitude at one-half of the first critical speed correspond to the $2 \times$ subcritical resonance and mainly to the crack effect.

So the comparisons of maximum amplitudes at one-half of the first critical speed between the rotor with and without an open crack can be applied to prognosis diagnosis of crack in a rotor system for low or high rotor's accelerations.

\subsection{Wavelet analysis with Continuous Wavelet Transform}

Due to the fact that the characteristics of transient responses cannot be precisely described and analyzed by means of the conventional spectrum cascade plots, the experiments will now be conducted at higher rotor accelerations to explore the effectiveness of the crack detection via the Continuous Wavelet Transform.

Firstly, a brief basic theory of the wavelet analysis is given. Then experimental tests for various high accelerations of the rotor system are investigated and the detection of cracks via the continuous wavelet transform are undertaken. 


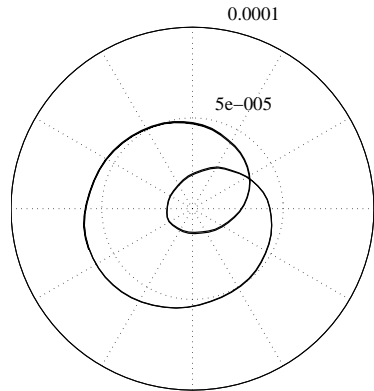

(a)

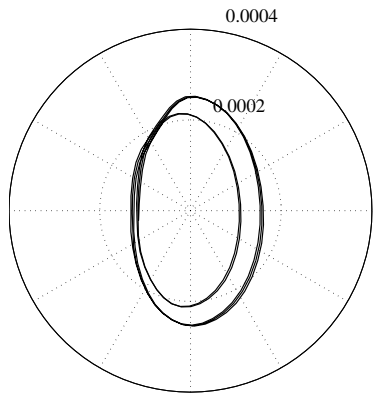

(e)

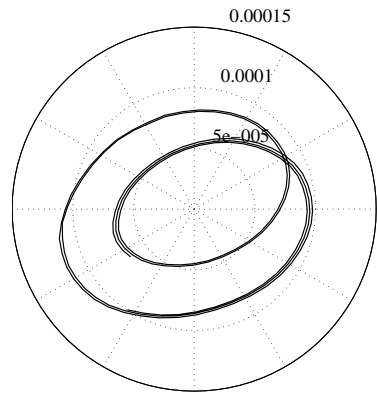

(b)

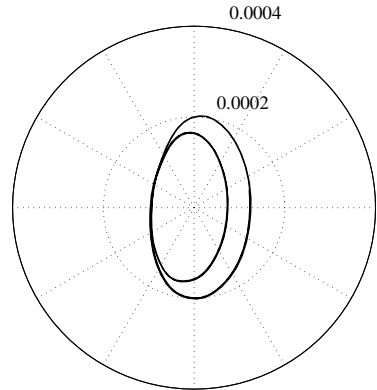

(f)

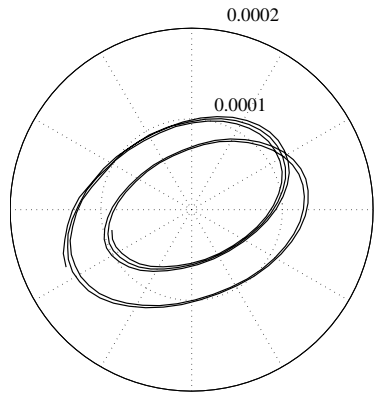

(c)

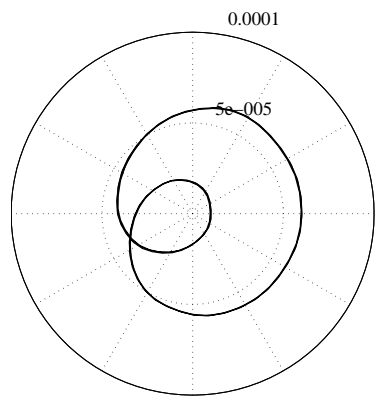

(g)

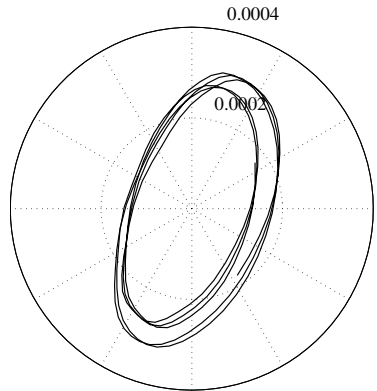

(d)

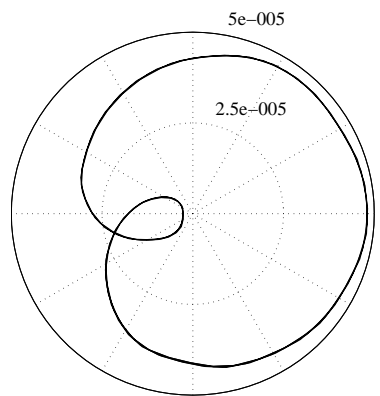

(h)

Figure 4: Evolutions of the orbital patterns at one-half of the first critical speed (from (a) to (h)) for the notched rotor at plane A2 (case 4)

\subsubsection{Basic theory}

The wavelet analysis transforms a signal into wavelets that are well localised both in frequency and time. The continuous wavelet transform (CWT) of a function $f(t)$ is a wavelet transform defined by

$$
W(a, b)=\int_{-\infty}^{+\infty} f(t) \psi_{a, b}^{*}(t) d t
$$

where

$$
\psi_{a, b}(t)=\frac{1}{\sqrt{a}} \psi\left(\frac{t-b}{a}\right)
$$

are the daughter wavelets (i.e. the dilated and shifted versions of the "'mother" wavelet $\psi$ that is continuous in both time and frequency). $a$ is the scale parameter, $b$ is the time parameter. The asterisk $\psi_{a, b}^{*}$ indicates the complex conjugate of $\psi_{a, b}$.

The following admissibility condition has to be satisfied $0<C_{\psi}<+\infty$ where $C_{\psi}$ defines the admissibility constant

$$
C_{\psi}=\int_{-\infty}^{+\infty} \frac{|\hat{\psi}(\omega)|^{2}}{|\omega|} d \omega
$$

and $\hat{\psi}$ is the Fourier transform of $\psi\left(\hat{\psi}=\int_{-\infty}^{+\infty} f(t) e^{i \omega t} d t\right)$. In this study, the Morlet mother wavelet has been chosen due to the fact that it is one of the most commonly used CWT wavelet (quite well localized in both time and frequency space). It is defined as following in the time domain:

$$
\psi_{0}(\eta)=\pi^{-\frac{1}{4}} e^{i m \eta} e^{-\frac{\eta^{2}}{2}}
$$



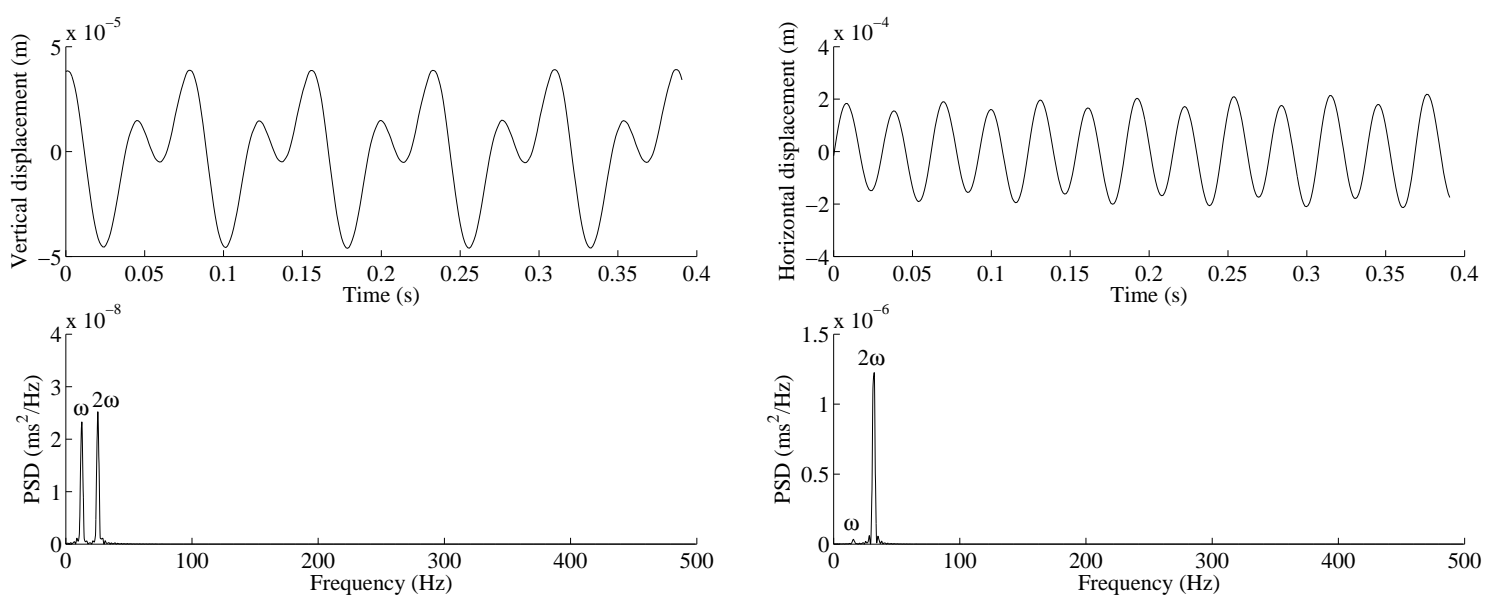

(a) plane A2 - vertical direction - $t=40 \mathrm{~s}$

(b) plane A2 - horizontal direction - $t=50 \mathrm{~s}$
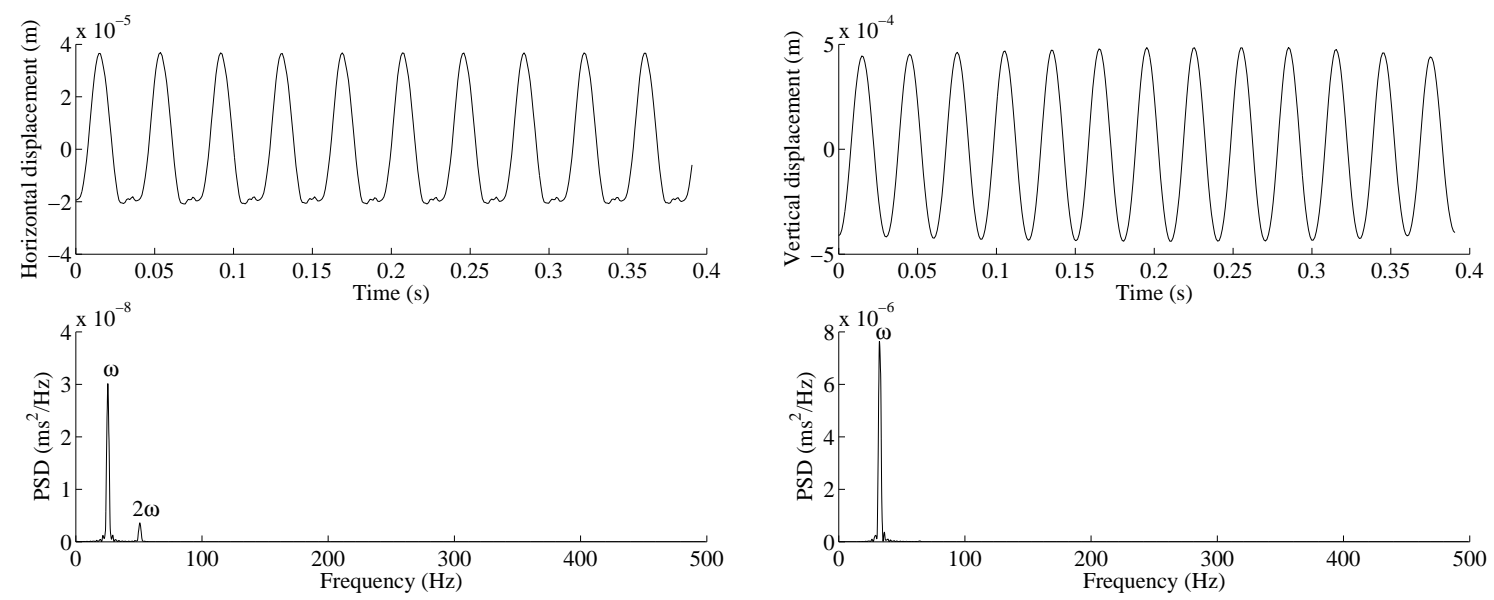

(c) plane A2 - vertical direction - $t=80 \mathrm{~s}$

(d) plane A2 - horizontal direction - $t=100 \mathrm{~s}$

Figure 5: Power Spectral Density in $m s^{2} / H z$ for the healthy rotor (a) before one-half of the first critical speed $(t=40 s)$, (b) at one-half of the first critical speed $(t=50 \mathrm{~s})$, (c) after one-half of the first critical speed $(t=80 s)$, (d) at the first critical speed $(t=100 s)$

where $m$ is the wavenumber and $\eta$ is non-dimensional time parameter.

For a time signal $f(t)$ represented by $N$ sampled data points (with uniform time step $\delta t$ ), the Continuous Wavelet Transform of Equation 2 is a convolution of the data sequence $f\left(n^{\prime}\right)$ (with $n^{\prime}=1, \ldots, N$ ) with a scaled and normalized wavelet. It can be represented as follows:

$$
C(a, n)=\sum_{n^{\prime}=0}^{N-1} f\left(n^{\prime}\right) \sqrt{\frac{\delta t}{a}} \Psi_{0}^{*}\left(\frac{\left(n^{\prime}-n\right) \delta t}{a}\right)
$$

where $n$ defines the localized time index and $\delta t$ is the sampling interval.

The wavelet function contains unit energy at every scale due to the normalization of the mother wavelet. Then, the wavelet power is defined as $|C(a, n)|^{2}$. 

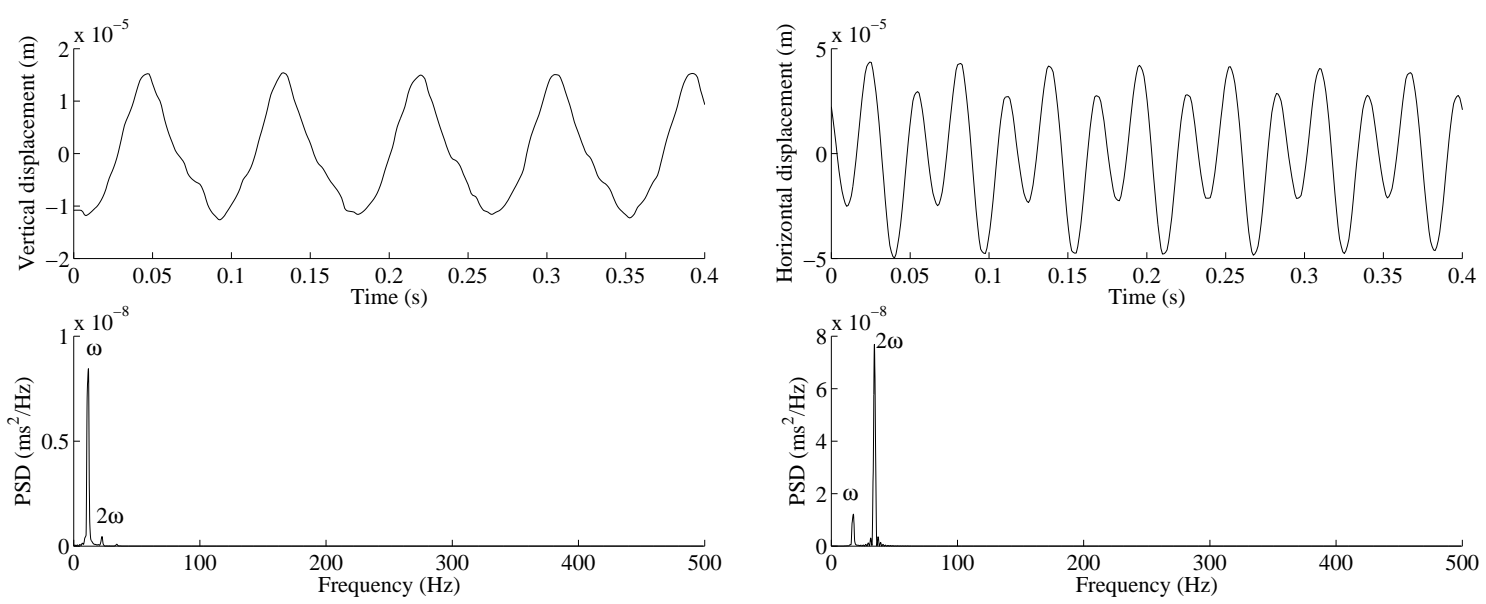

(a) plane A2 - vertical direction - $t=40 \mathrm{~s}$

(b) plane A2 - horizontal direction $-t=50 \mathrm{~s}$
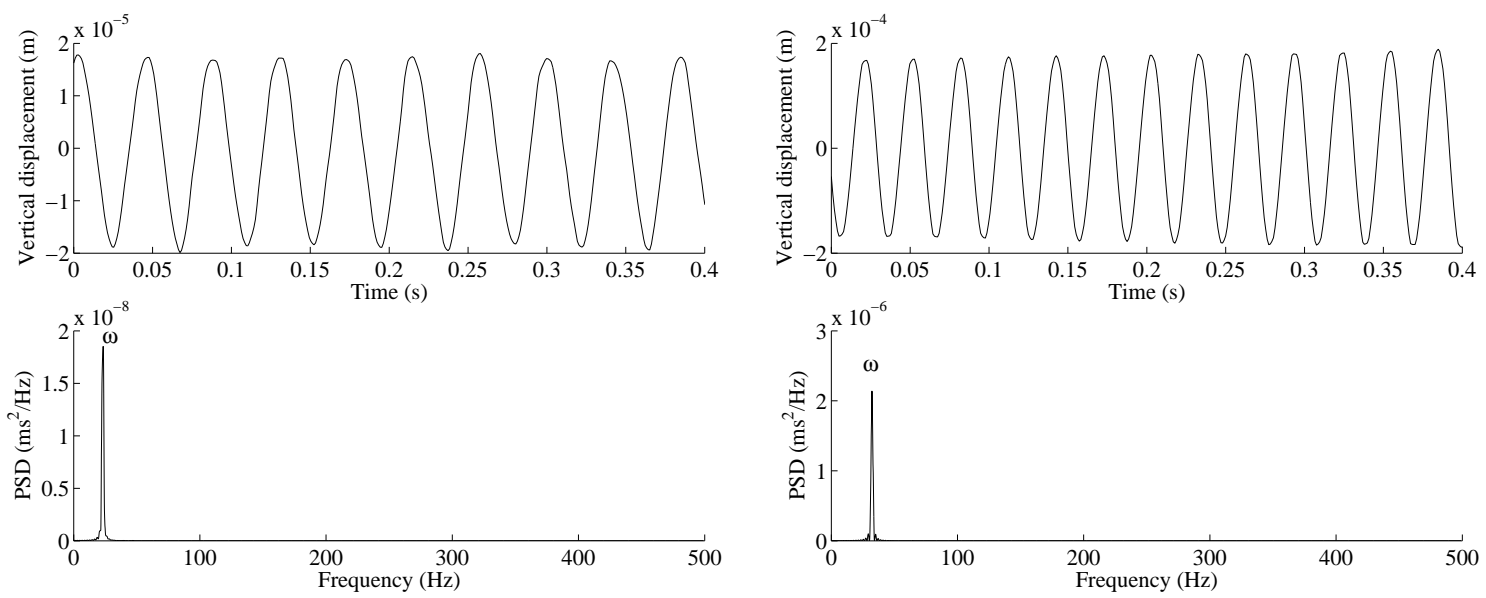

(c) plane A2 - vertical direction - $t=80 \mathrm{~s}$

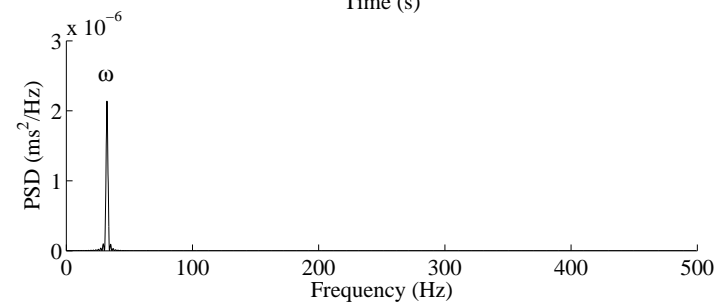

(d) plane A2 - horizontal direction - $t=100 \mathrm{~s}$

Figure 6: Power Spectral Density in $m s^{2} / \mathrm{Hz}$ for the notched rotor (a) before one-half of the first critical speed $(t=40 s)$, (b) at one-half of the first critical speed $(t=50 \mathrm{~s})$, (c) after one-half of the first critical speed $(t=80 s),(d)$ at the first critical speed $(t=100 s)$

\subsubsection{Crack detection using wavelet transform}

First of all, the wavelet analysis is used to compare the transient responses of the rotor with and without an open crack. Figure 11 shows the normalized wavelet power spectrum $\frac{|C(a, n)|^{2}}{\sigma^{2}}$ where $\sigma^{2}$ is the variance [32] for the two cases previously detailed in Section 3.1). Comparing Figure 11(a) and (b), the conclusion is that the continuous wavelet transform can identify the notched rotor effectively. The top figure correspond to the horizontal direction and the bottom to the vertical direction. It clearly appears that the presence of a transverse crack induces the appearance of a second maximum value of the normalized wavelet power spectrum (which corresponds to the sub-harmonic resonance of the notched rotor) when the rotor is passing through one-half the first critical speed (for $t \in[45-50] s$ ). These results reflect the previous observations done in Figures 7. 


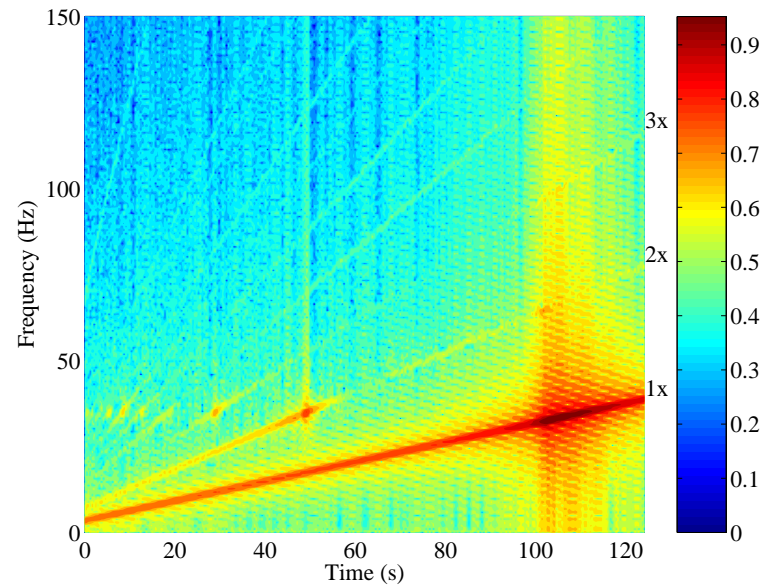

(a) healthy rotor - vertical direction

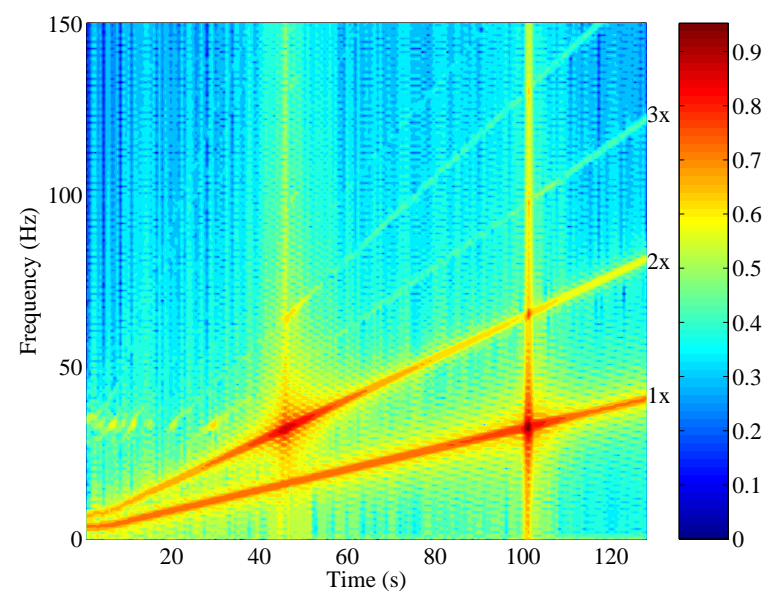

(c) notched rotor - vertical direction

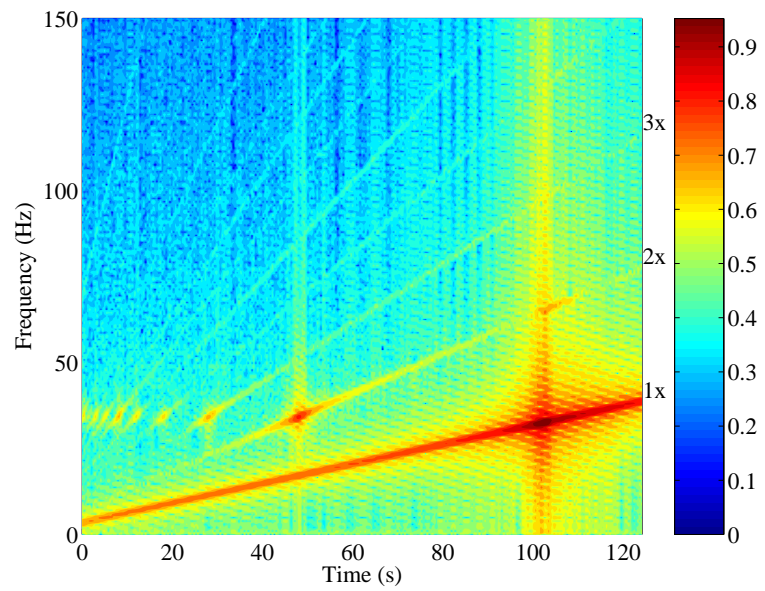

(b) healthy rotor - horizontal direction

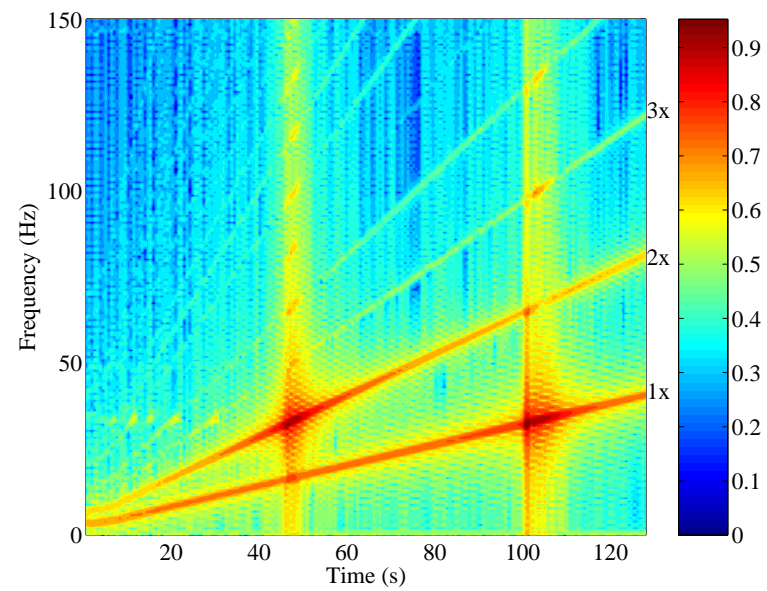

(d) notched rotor - horizontal direction

Figure 7: Spectrum cascade plots of the normalized Power Spectral Density in logscale for the rotor with and without crack for both the vertical and horizontal directions at plane A2 (with an acceleration of $20 \mathrm{rpm} . \mathrm{s}^{-1}$ )

Now the experiments are conducted at higher rotor accelerations to explore the effectiveness of the crack detection via the Continuous Wavelet Transform. The measured vibration behaviour of the rotor both in vertical and horizontal directions in time are shown in Figures 12(a), (c) and (e) for Cases 6, 8 and 11 (see Table 1). The associated normalized wavelet power spectrum are given in Figures 12(b), (d) and (f). It clearly appears that there is no significant change in performance of the detection of crack via the continuous wavelet transform with high rotor accelerations : near the rotational speeds at the $\frac{1}{2}$ of the first critical speed for the rotor, the normalized wavelet power spectrum increases drastically indicating the presence of the transverse open crack in the rotating machinery. The wavelet power spectrum consists of both unbalance and crack effects : the first peak corresponds mainly to the crack effect and the associated $2 \times$ sub-critical resonance and the other, mainly to the unbalance and the interaction with the crack.

Finally, Figures 13 give the normalized wavelet power spectrum for two unbalance cases. Even if the unbalance is important (see Figure 10(a)), the first peak at one half of the critical speed is predominant 


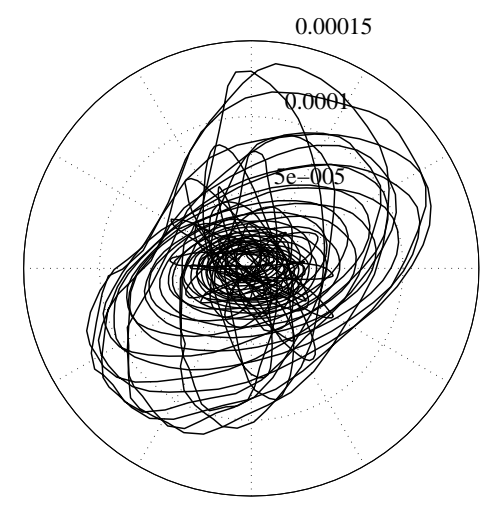

(a) plane A1

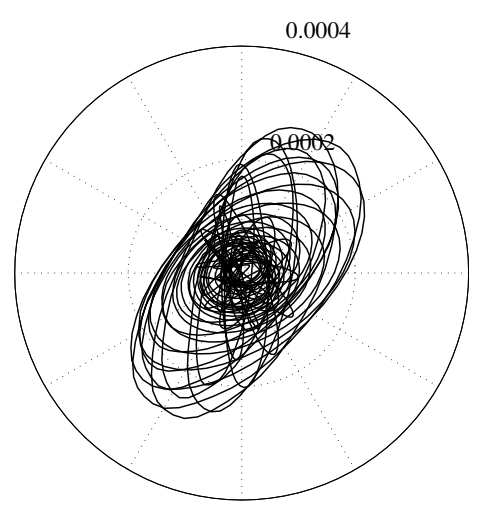

(b) plane A2

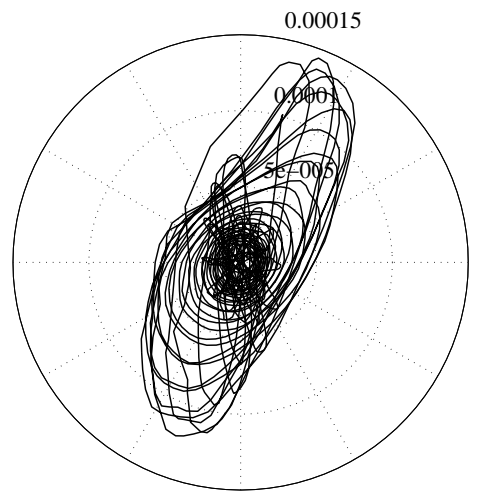

(c) plane A3

Figure 8: Transient orbital patterns for $t \in[4-5] \mathrm{s}$ with an acceleration of $230 \mathrm{rpm}_{\mathrm{s}} \mathrm{s}^{-1}$ (case 11)

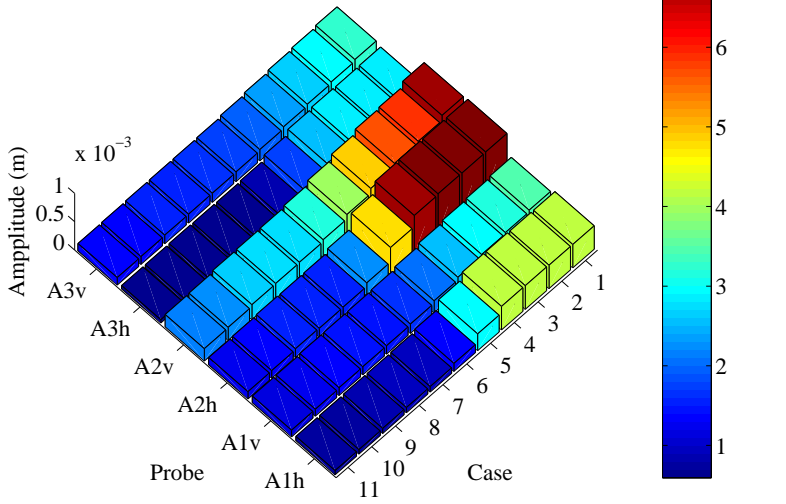

(a) at the critical speed

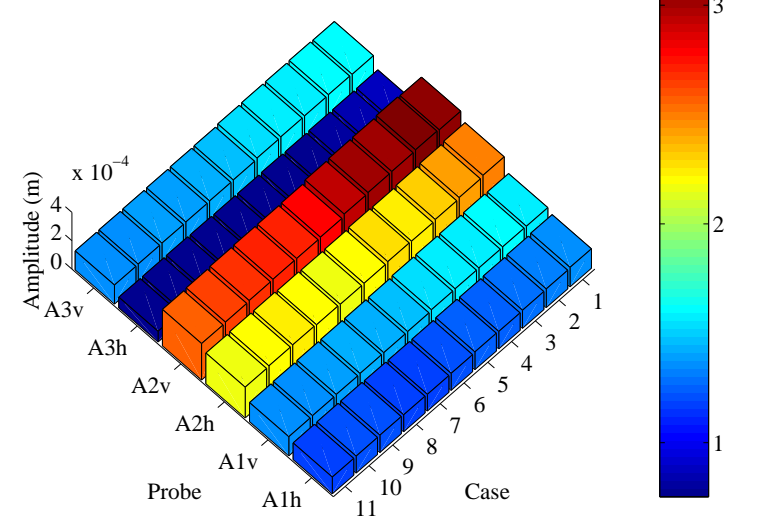

(b) at $\frac{1}{2}$ of the critical speed

Figure 9: Maximum amplitudes at one-half of the first critical speed and at the critical speed for various rotor's accelerations (Aiv: vertical amplitude for the $i^{\text {th }}$ plane, Aih: horizontal amplitude for the $i^{t h}$ )

and the wavelet analysis can be used to identify the presence of a crack in rotating machinery.

In conclusion, the change in the wavelet power spectrum and the transient dynamic behavior of the notched rotor can be used as a diagnosis feature for low and high rotor's accelerations.

\section{Conclusion}

In this paper, it is demonstrated that the diagnosis of the presence of a transverse open crack based on the transient vibration signals during machine run-up can be easily done by using various appropriated tools.

For steady-state vibration signals (low rotor's accelerations), the traditional spectrum cascade plots of the power spectral density and the evolution of orbits patterns with the classical two-loops orbit can be 


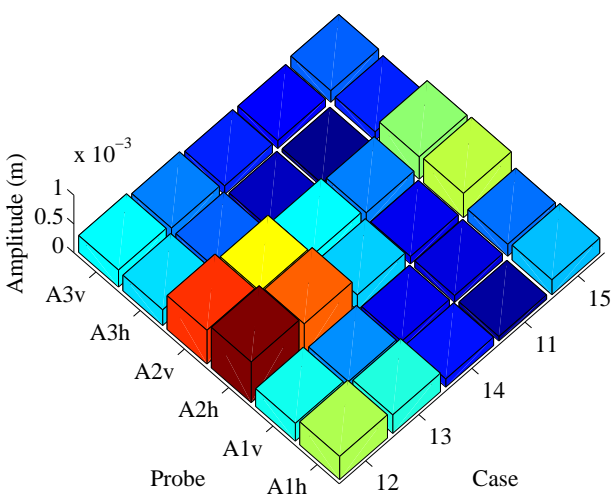

(a) at the critical speed
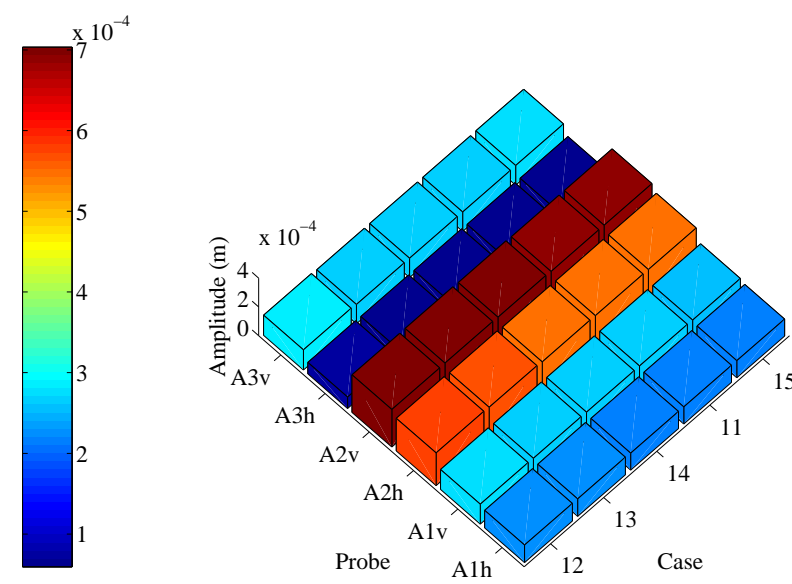

(b) at $\frac{1}{2}$ of the critical speed

Figure 10: Maximum amplitudes at one-half of the first critical speed and at the critical speed for various disc's unbalance (Aiv: vertical amplitude for the $i^{t h}$ plane, Aih: horizontal amplitude for the $i^{t h}$ )

used to detect the presence of open cracks. Moreover, the $2 \times$ harmonic components at one-half the first critical speed is one of the most effectiveness indicators for crack detection.

For transient vibration signals with higher accelerations of the rotor system, the wavelet transforms can be applied to detect open cracks in rotors. In this present study, it is demonstrated that changes on the $2 \times$ harmonic components based on the continuous wavelet transform can been successfully used and appears to be an ideal tool for detecting crack with signals of a transient or non-stationary nature. : the $2 \times$ harmonic components are predominant not only at one-half of the first critical speed but also in its vicinity. So, the presence of an open transverse crack can be detected even of the rotor's acceleration is very high.

\section{Acknowledgments}

The author would like to thank the financial support of the financial support of the french National Research Agency through the program Young researcher ANR-07-JCJC-0059-01-CSD 2, the Centre National de la Recherche Scientifique and the laboratory LTDS UMR-CNRS 5513 (Laboratoire de Tribologie et Dynamique des Systmes, Unit Mixte de Recherche du Centre National de la Recherche Scientifique 5513) to carry out this research. Some of CWT software includes code originally written by C.Torrence and G. Compo (http://paos.colorado.edu/research/wavelets/).

\section{References}

[1] Wauer, J., 1990. "Dynamics of cracked rotors: Literature survey". Applied Mechanics Review, 43, pp. $13-17$.

[2] Dimarogonas, A., 1996. "Vibration of cracked structures: a state of the art review". Engineering Fracture Mechanics, 55, p. 831-857. 


\begin{tabular}{ccc}
\hline & & \\
Case & Acceleration $\left(r p m . s^{-1}\right)$ & Unbalance $(g . m)$ \\
\hline 1 & 2.4 & 0.8 \\
2 & 6.1 & 0.8 \\
3 & 11.4 & 0.8 \\
4 & 20 & 0.8 \\
5 & 28.2 & 0.8 \\
6 & 58.8 & 0.8 \\
7 & 98 & 0.8 \\
8 & 111 & 0.8 \\
9 & 141 & 0.8 \\
10 & 182 & 0.8 \\
11 & 230 & 0.8 \\
12 & 230 & 0.2 \\
13 & 230 & 0.4 \\
14 & 230 & 0.6 \\
15 & 230 & 1 \\
\hline
\end{tabular}

Table 1: Rotor's acceleration and disc's unbalance for Cases 1 to 15

[3] Montalvao, D., Maia, N., and Ribeiro, A., 2006. "A review of vibration-based structural health monitoring with special emphasis on composite materials". The Shock and Vibration Digest, 38(4), pp. 1-30.

[4] Doebling, S., Farrar, C., Prime, M., and Shevitz, D., 1996. Damage Identification and Health Monitoring of Structural and Mechanical Systems from Changes in Their Vibration Characteristics: A Literature Review. Technical Report LA-13070-MS, Los Alamos National Laboratory Report.

[5] Sohn, H., Farrar, C., Hemez, F., Shunk, D., Stinemates, D., and Nadler, B., 2003. A Review of Structural Health Monitoring Literature : 1996-2001. Technical Report LA-13976-MS, Los Alamos National Laboratory Report.

[6] Salawu, O. S., 1997. "Detection of structural damage through changes in frequency: a review". Engineering Structures, 19(9), pp. 718-723.

[7] Imam, I., Azarro, S., Bankert, R., and Scheibel, J., 1989. "Development of an on-line rotor crack detection and monitoring system". Journal of Vibration, Acoustics, Stress and Reliability in Design, 3, p. 241-250.

[8] Sinou, J.-J., 2007. "Damage assessment based on the frequencies' ratio surfaces intersection method for the identification of the crack depth, location and orientation". Structural Durability and Health Monitoring, 3(3), pp. 134-162.

[9] Davies, W. G. R., and Mayes, I. W., 1984. "The vibrational behaviour of a multi-shaft, multibearing system in the presence of a propagating transverse crack". Transactions of the ASME Journal of Vibration, Acoustics, Stress, and Reliability in Design, 106, pp. 146-153. 

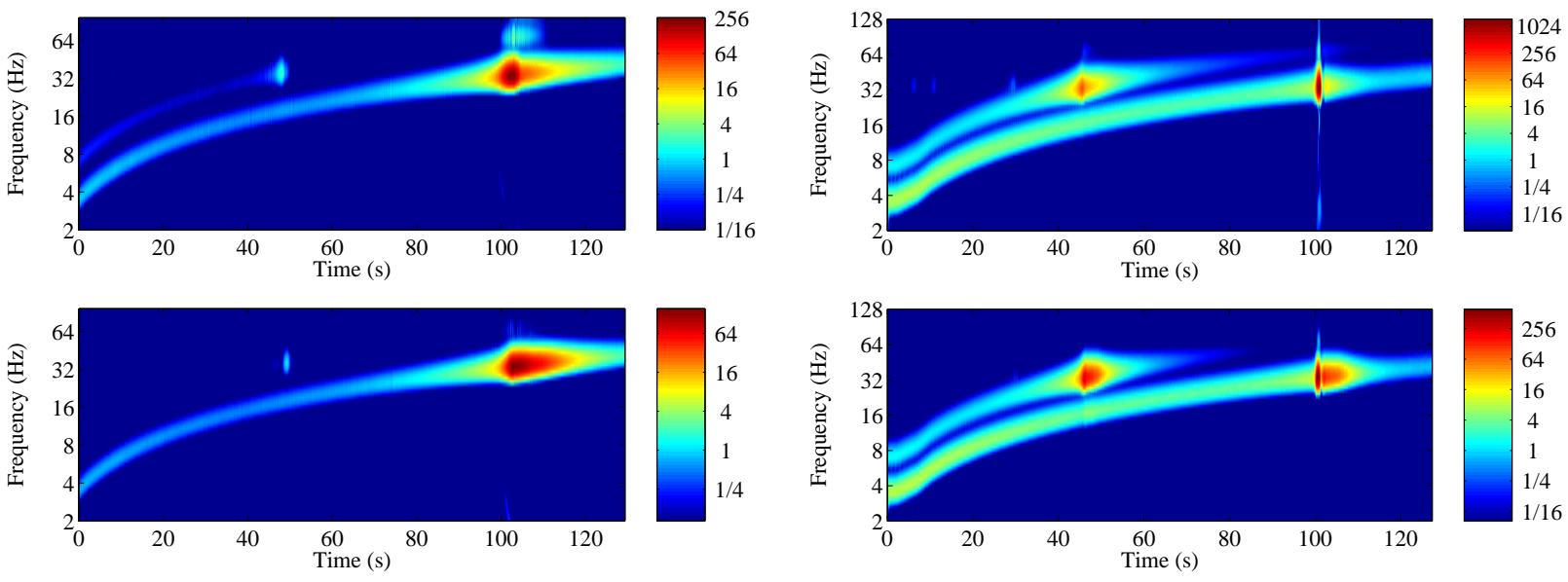

(a) healthy rotor

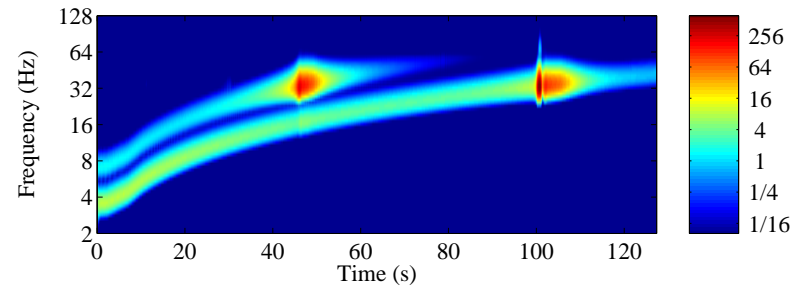

(b) notched rotor

Figure 11: Wavelet power spectrum for the notched and healthy rotors at plane A2 (top $=$ horizontal direction, bottom $=$ vertical direction)

[10] Mayes, I. W., and Davies, W. G. R., 1984. "Analysis of the response of a multi-rotor-bearing system containing a transverse crack in a rotor". Transactions of the ASME Journal of Vibration, Acoustics, Stress, and Reliability in Design, 106, pp. 139-145.

[11] Gasch, R., 1993. "A survey of the dynamic behavior of a simple rotating shaft with a transverse crack". Journal of Sound and Vibration, 160, p. 313-332.

[12] Pu, Y., Chen, J., Zou, J., and Zhong, P., 2002. "Quasi-periodic vibration of cracked rotor on flexible bearings". Journal of Sound and Vibration, 251(5), p. 875-890.

[13] Zhu, C., Robb, D., and Ewins, D., 2003. "The dynamics of a cracked rotor with an active magnetic bearing”. Journal of Sound and Vibration, 265, p. 469-487.

[14] Sinou, J.-J., and Lees, A. W., 2005. "Influence of cracks in rotating shafts". Journal of Sound and Vibration, 285(4-5), pp. 1015-1037.

[15] Adewusi, S., and Al-Bedoor, B., 2002. "Experimental study on the vibration of an overhung rotor with a propagating transverse crack". Shock and Vibration, 9, p. 91-104.

[16] Sinou, J.-J., 2007. "Effects of a crack on the stability of a non-linear rotor system". International Journal of Non-Linear Mechanics, 42, p. 959 - 972.

[17] Bachschmid, N., Pennacchi, P., and Vania, A., 2002. "Identification of multiple faults in rotor systems,". Journal of Sound and Vibration, 254(2), pp. 327-366.

[18] Pennacchi, P., Bachschmid, N., and Vania, A., 2006. "A model-based identification method of transverse cracks in rotating shafts suitable for industrial machines". Mechanical Systems and Signal Processing, 20, p. 2112-2147.

[19] Darpe, K., Gupta, K., and Chawla, A., 2003. "Experimental investigations of the response of a cracked rotor to periodic axial excitation". Journal of Sound and Vibration, 260(2), pp. 265-286. 
[20] Han, D., 2007. "Vibration analysis of periodically time-varying rotor system with transverse crack". Mechanical Systems and Signal Processing, 21, p. 2857-2879.

[21] Prabhakar, S., Sekhar, A., and Mohanty, A., 2002. "Transient lateral analysis of a slant-cracked rotor passing through its flexural critical speed". Mechanism and Machine Theory, 37, p. 10071020 .

[22] Sekhar, A., 2004. "Detection and monitoring of crack in a coast-down rotor supported on fluid film bearings". Tribology International, 37, p. 279-287.

[23] Darpe, A., 2007. "A novel way to detect transverse surface crack in a rotating shaft". Journal of Sound and Vibration, 305, p. 151-171.

[24] Sekhar, A., and Prabhu, B., 1998. "Condition monitoring of cracked rotors through transient response". Mechanism and Machine Theory, 33(8), pp. 1167-1175 .

[25] Sekhar, A. S., 2003. "Crack detection and monitoring in a rotor supported on fluid film bearings: Start-up vs run-down”. Mechanical Systems and Signal Processing, 17(4), p. 897-901.

[26] Sekhar, A., 2003. "Crack detection through wavelet transform for a run-up rotor". Journal of Sound and Vibration, 259, p. 461-472 .

[27] Adewusi, S., and Al-Bedoor, B., 2001. "Wavelet analysis of vibration signal of an overhang rotor with a propagating transverse crack". Journal of Sound and Vibration, 246, p. 777-793.

[28] YanPing, Z., ShuHong, H., JingHong, H., Tao, S., and Wei, L., 2006. "Continuous wavelet grey moment approach for vibration analysis of rotating machinery". Mechanical Systems and Signal Processing, 20, p. 1202-1220.

[29] Gaul, L., and Hurlebaus, S., 1998. "Identification of the impact location on a plate using wavelets". Mechanical Systems and Signal Processing, 12(6), p. 783-795.

[30] Junsheng, C., Dejie, Y., and Yu, Y., 2005. "Application of an impulse response wavelet to fault diagnosis of rolling bearings". Mechanical Systems and Signal Processing, 21, p. 920929.

[31] Sabnavis, G., Kirk, R. G., Kasarda, M., and Quinn, D., 2004. "Cracked shaft detection and diagnostics: A literature review". The Shock and Vibration Digest, 36(4), pp. 287-296.

[32] Torrence, C., and Compo, G., 1998. "A practical guide to wavelet analysis". Bulletin of the American Meteorological Society, 79(1), pp. 61-78. 

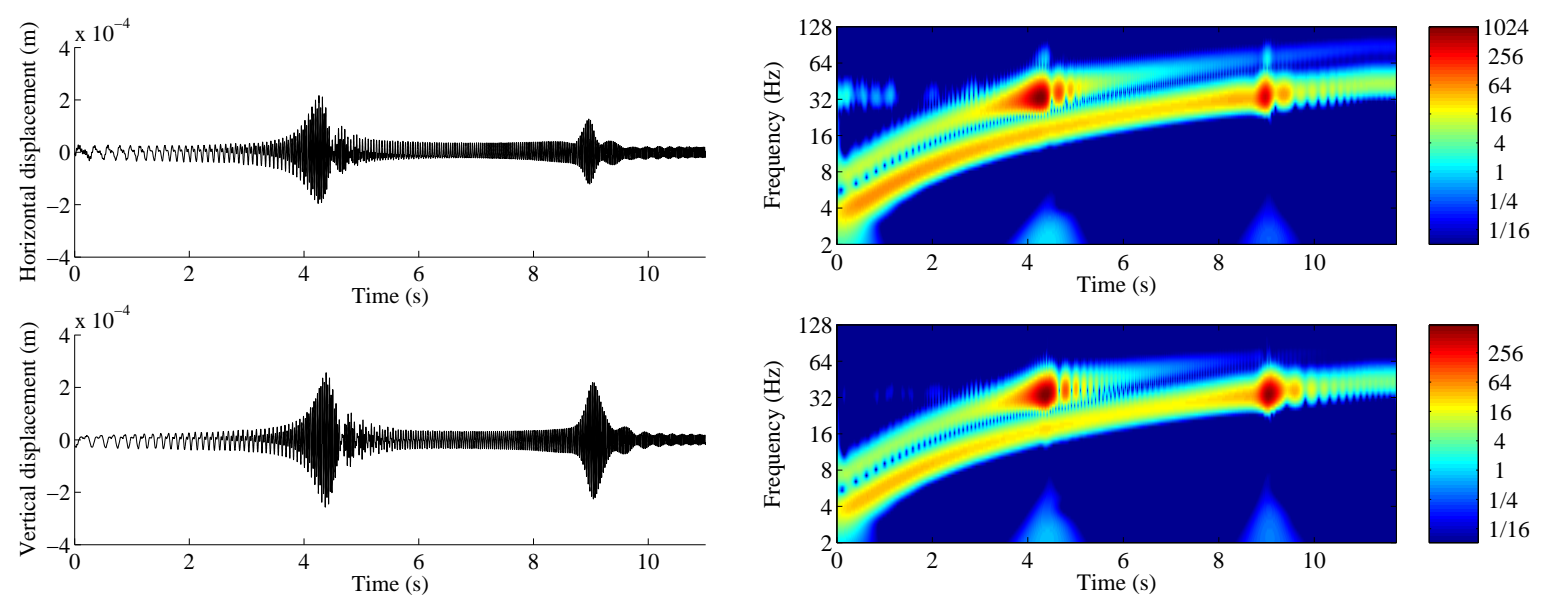

(a) transient responses $-230 \mathrm{rpm} . \mathrm{s}^{-1}$

(b) Power spectrum - 230rpm.s s $^{-1}$
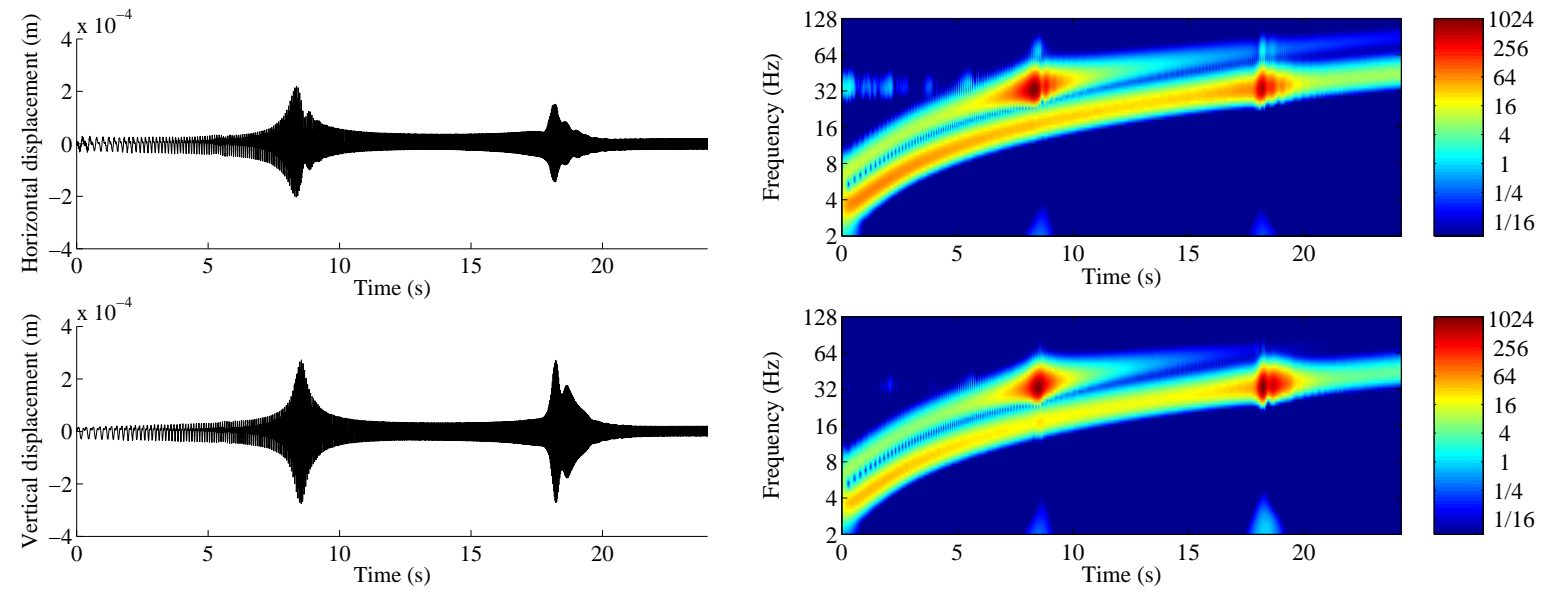

(c) transient responses - 111rpm.s $\mathrm{s}^{-1}$

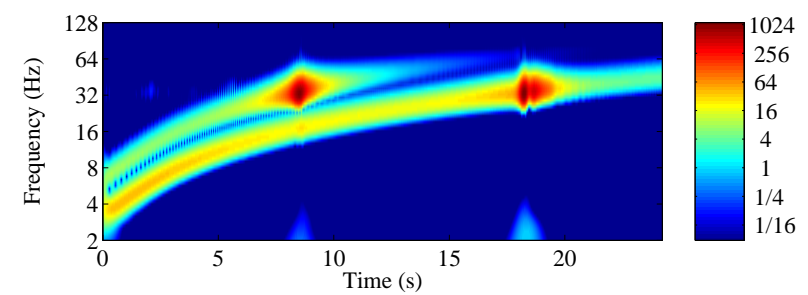

(d) Power spectrum - 111rpm.s s $^{-1}$
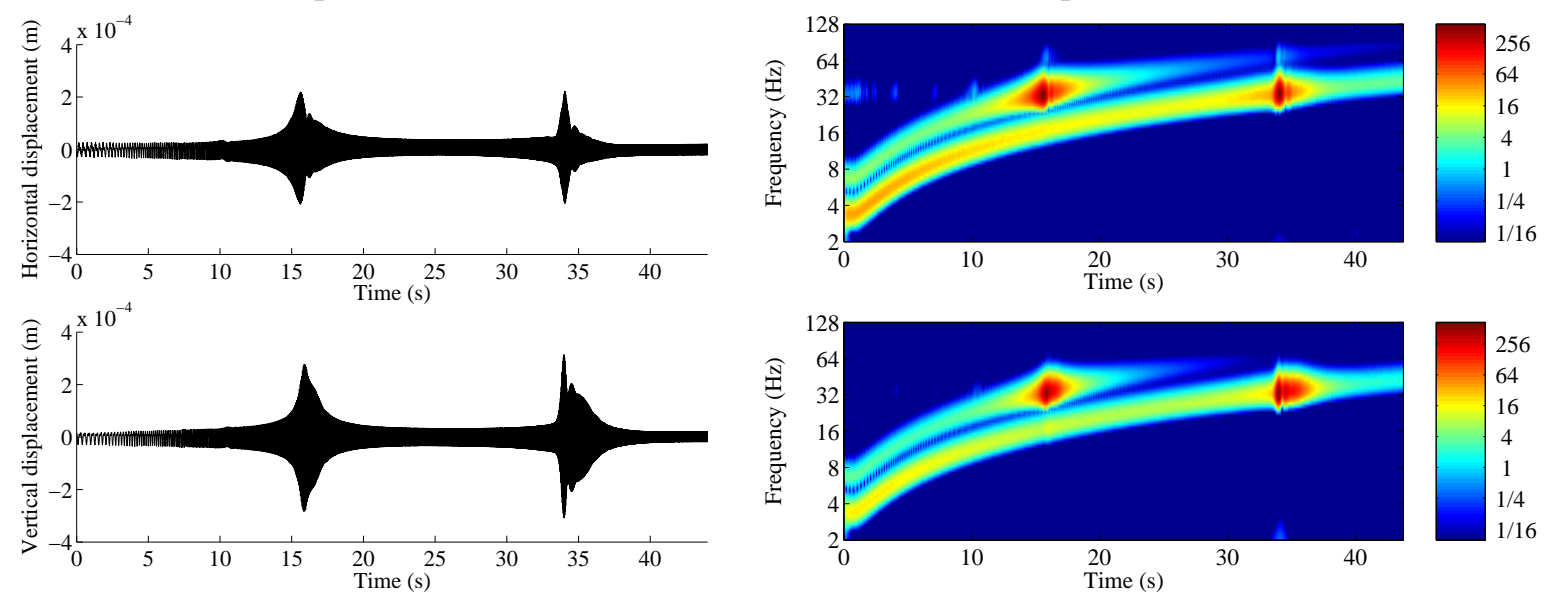

(e) transient responses - 58.8rpm.s $\mathrm{s}^{-1}$

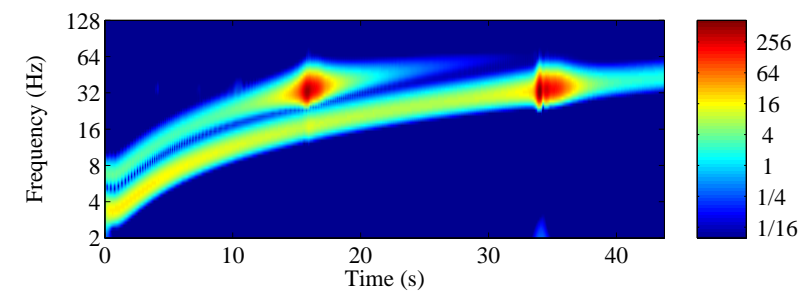

(f) Power spectrum - 58.8rpm.s $\mathrm{s}^{-1}$

Figure 12: Transient responses and wavelet power spectrum for the horizontal and vertical directions (plane A2) and three accelerations : (a-b) case 11, (c-d) case 8, (e-f) case 6. 

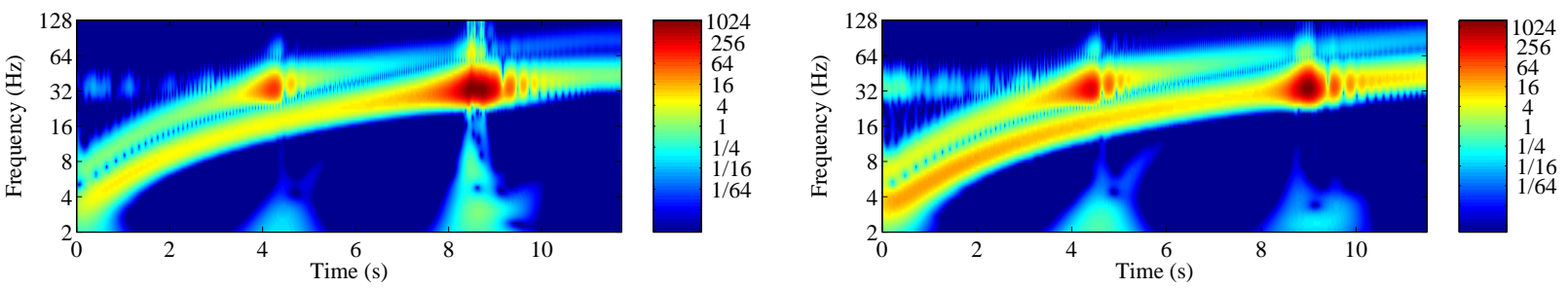

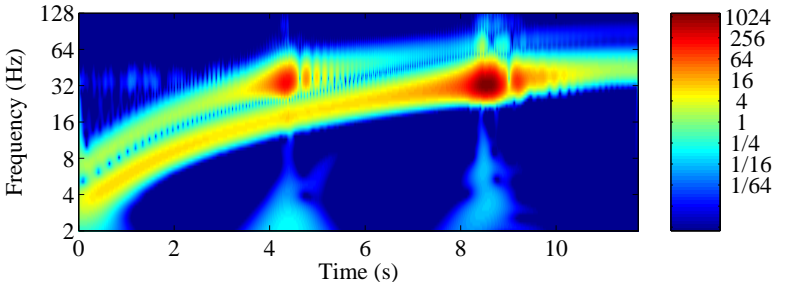

(a) case $12-0.2 \mathrm{~g} . \mathrm{m}$

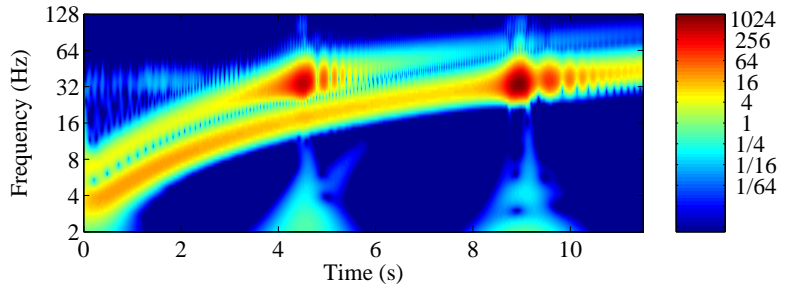

(b) case 15 - $1 \mathrm{~g} \cdot \mathrm{m}$

Figure 13: Wavelet power spectrum for two unbalances at plane A2 (top = horizontal direction, bottom = vertical direction) 